\title{
Anastomotic Leak after Esophagectomy for Esophageal Cancer Treated with a Stent: A Case Report
}

\author{
Mohamed Ahmed ${ }^{1}$, Saba Habis ${ }^{2}$, Ahmed Mahmoud ${ }^{1}$, Michael Chin ${ }^{1}$, Rasha Saeed ${ }^{1}$ \\ 1. Surgery, Riverside Community Hospital, Riverside, USA 2. Internal Medicine, Riverside Community Hospital, \\ Riverside, USA
}

Corresponding author: Mohamed Ahmed, maamsmd@yahoo.com

\begin{abstract}
Intrathoracic esophageal anastomotic leaks after cancer resection are very morbid and challenging problems. Esophageal stents play an integral role in the management of these patients. Herein, we present a case of lower esophageal cancer who developed a leak at his gastroesophageal anastomosis after resection and was successfully managed with a fully covered metal stent. Our objective was to remind our colleagues regarding a safe alternative treatment for this complication.
\end{abstract}

Categories: Gastroenterology, General Surgery, Oncology

Keywords: esophageal cancer, leak, stent, anastamosis

\section{Introduction}

Upper gastrointestinal tract surgery can result in $4 \%$ to $8 \%$ anastomotic leaks with a $35 \%$ mortality rate [13]. Return to the operating room is difficult due to an infected field in morbidly ill patients and carries a risk of further complications. Minimally invasive endoscopic implantation of self-expandable covered stents in the area of the fistula accompanied by drainage can result in healing with minimal morbidity [4].

\section{Case Presentation}

A 58-year-old male underwent Ivor Lewis procedure for a T2N0 well-differentiated adenocarcinoma of the distal esophagus. The patient did well until postoperative day six when he became febrile (temperature of $102{ }^{\circ} \mathrm{F}$ ) and his white cell count rose to $21 \mathrm{k} / \mathrm{mm}^{3}$. Chest computed tomography (CT) scan revealed a frank anastomotic leak (Figure 1) with a loculated abscess formation (Figure 2).

\footnotetext{
Received 02/04/2019

Review began 02/06/2019

Review ended 02/10/2019

Published 02/12/2019

๑) Copyright 2019

Ahmed et al. This is an open access

article distributed under the terms of the

Creative Commons Attribution License

CC-BY 3.0., which permits unrestricted

use, distribution, and reproduction in any

medium, provided the original author and source are credited.
} 


\section{Cureus}

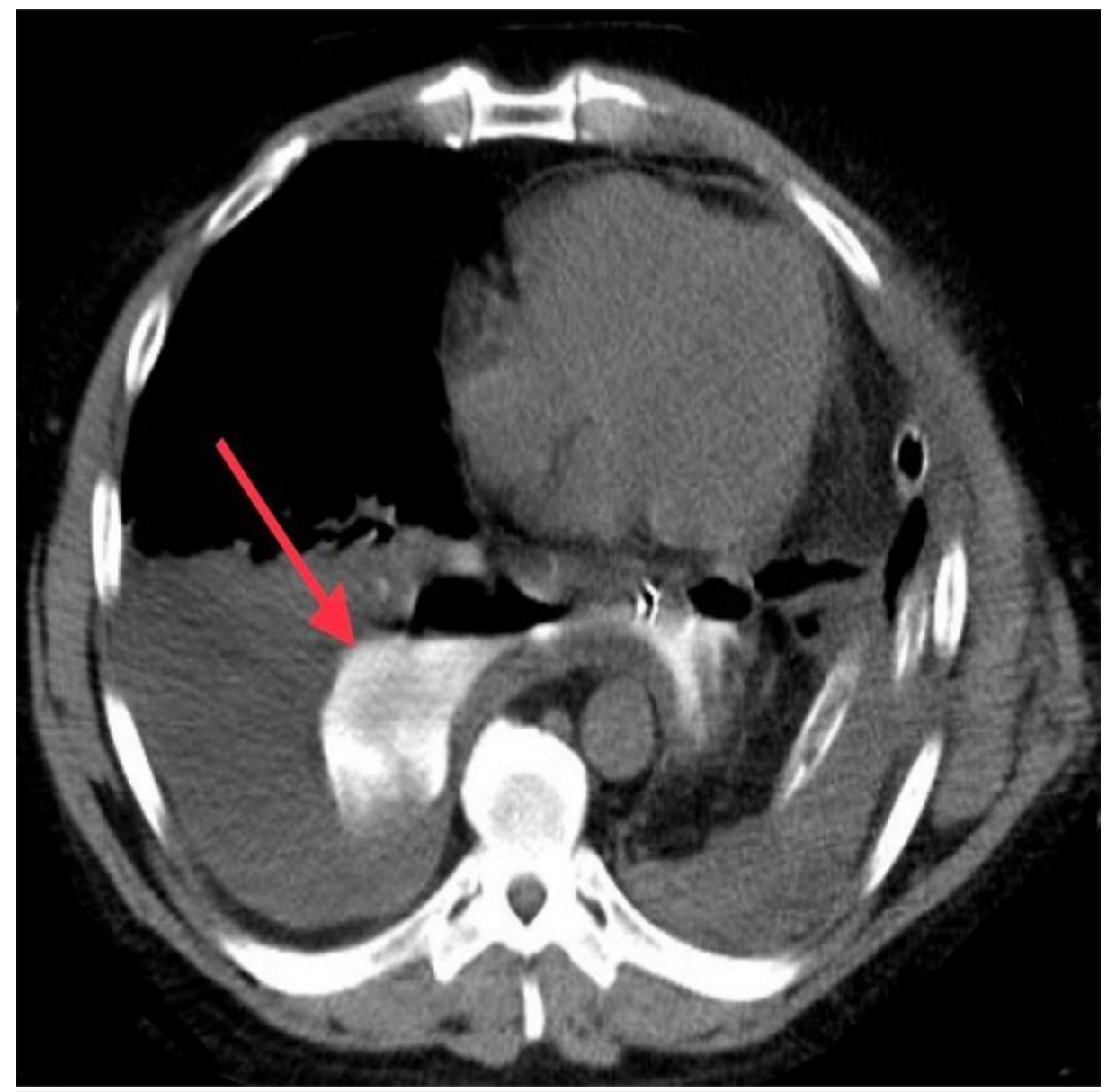

FIGURE 1: Chest CT scan with oral contrast

Anastomotic leak into the right pleural cavity (red arrow)

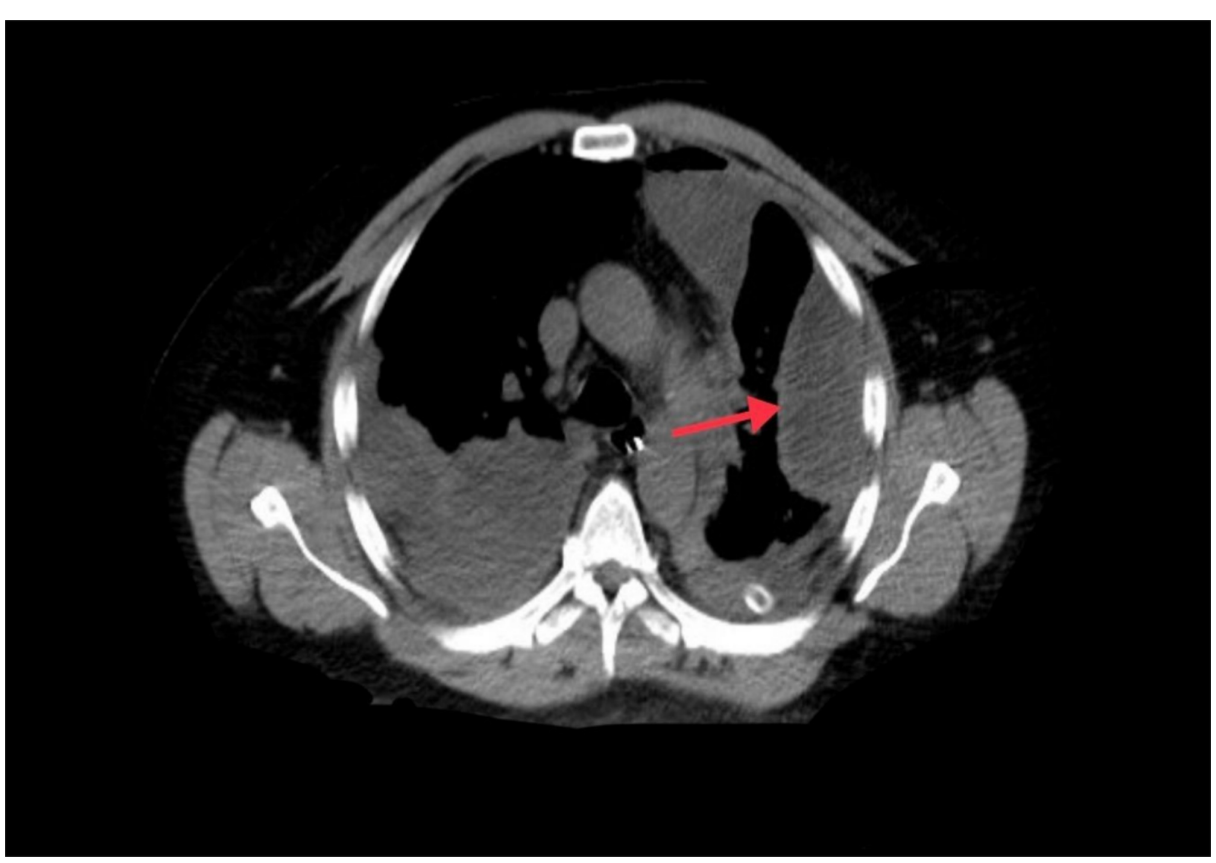

FIGURE 2: Chest CT scan

Loculated abscess (red arrow) 


\section{Cureus}

A chest tube was inserted to drain the abscess, control the leak, and obtain microbiological cultures. Broadspectrum antibiotics coverage was initiated in the form of metronidazole $500 \mathrm{mg}$ intravenous every eight hours and ceftriaxone $2 \mathrm{~g}$ intravenous every 24 hours. Esophagogastroscopy revealed a 1-cm disruption at the gastroesophageal anastomosis and a 23-French (diameter), 8-cm (length) fully covered metal stent was deployed by our gastroenterologist to cover the leaking area (Figure 3).

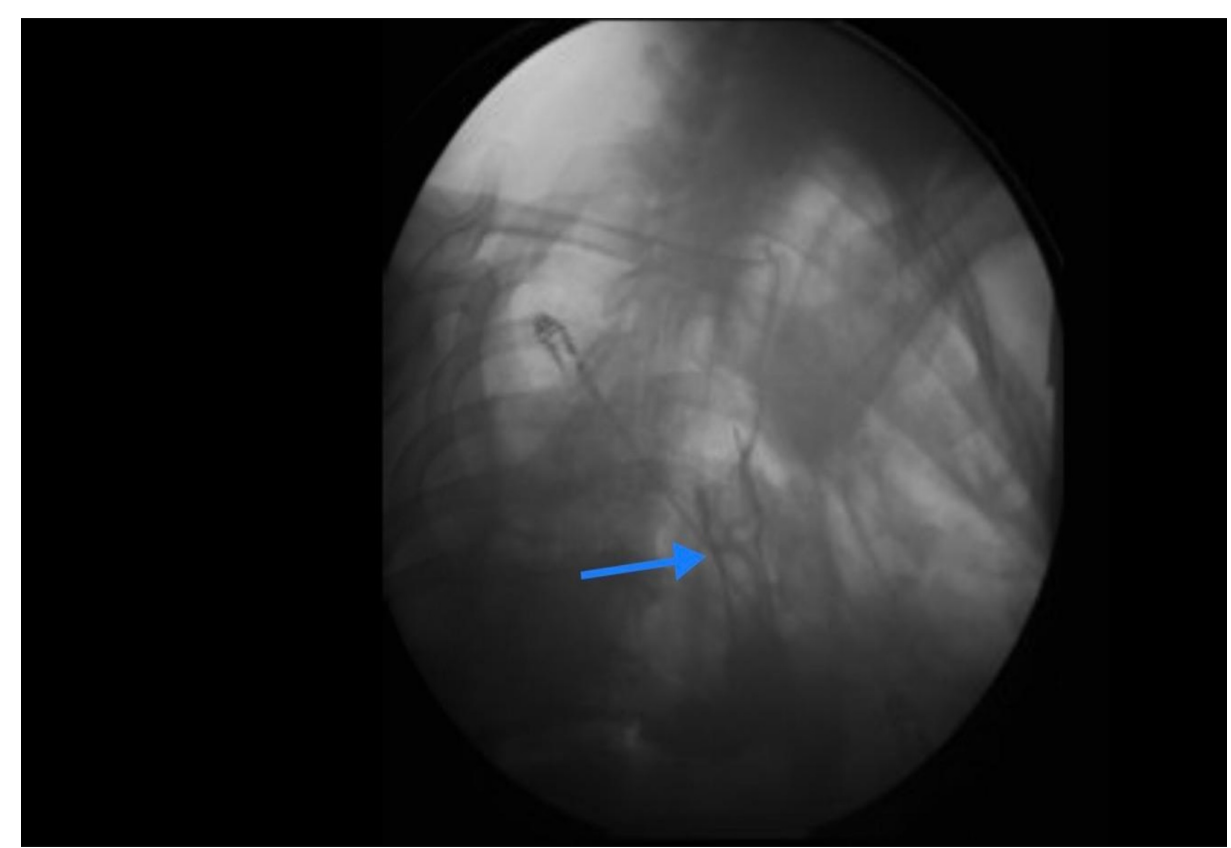

\section{FIGURE 3: Flouroscopy to guide stent placement}

Metal stent (blue arrow)

Patient condition dramatically improved after stent placement with normalization of his temperature and white count. Esophagogram a week later demonstrated control of the leak (Figure 4).

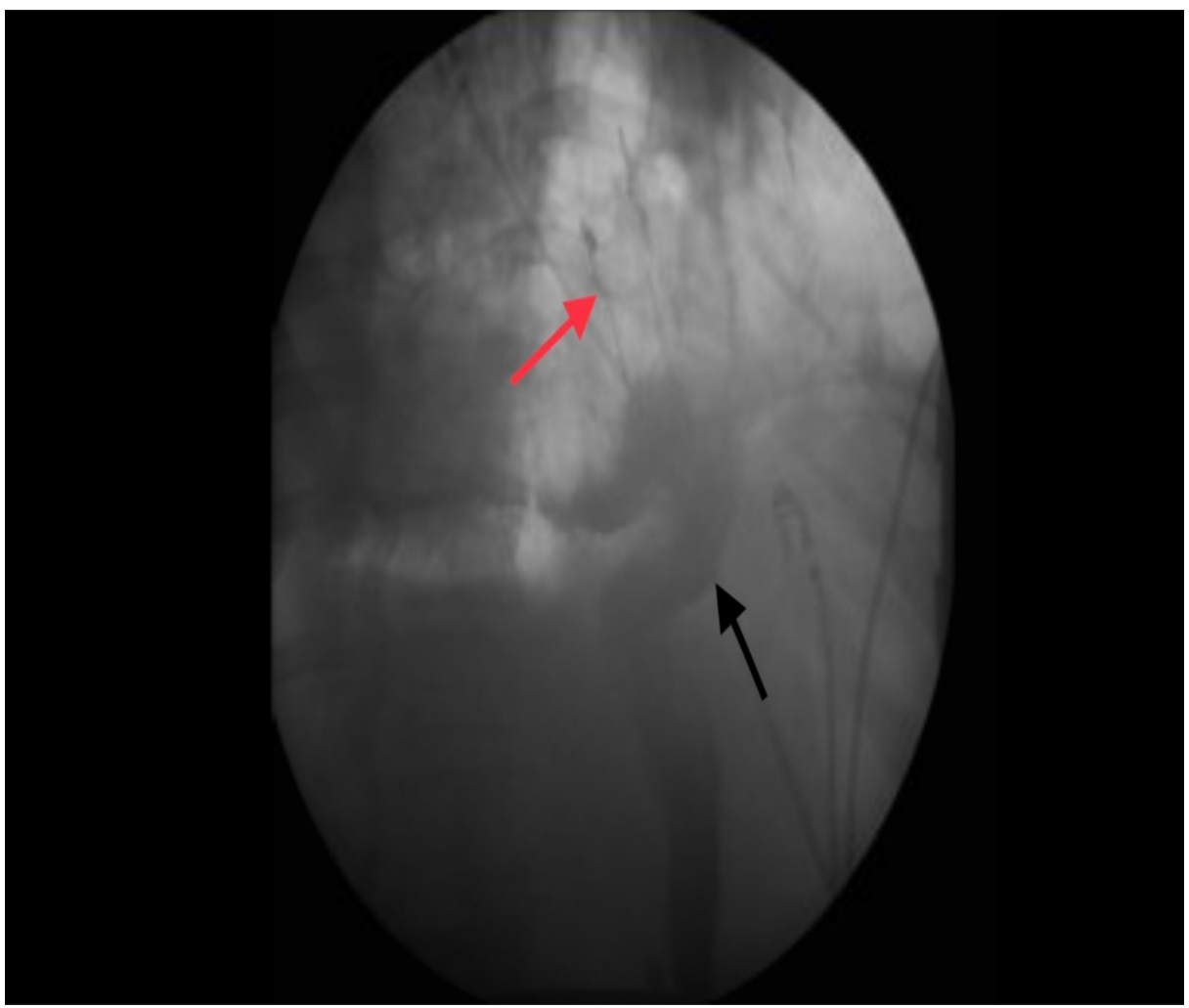


FIGURE 4: Esophagogram

Stent in place (red arrow); stomach remnant (black arrow)

The patient did well and was discharged from the hospital.

\section{Discussion}

Esophagogastric anastomotic leakage is defined as dehiscence of the esophagogastrostomic anastomosis [5]. Risk factors can be subdivided into systemic disease (malnutrition, smoking, diabetes, cardiovascular disease, age, hypoxemia, preoperative chemoradiation, and reduced physical working capacity), operative and postoperative factors (tension at the anastomosis, blood supply, excessive intraoperative bleed, surgeon experience, postoperative distention, and prolonged mechanical ventilation) [6]. The extent of the leak is categorized as contained (small area of contrast extravasation that is contained by mediastinal structures) or uncontained (large leak with contrast freely flowing into the pleural space) based upon appearance on imaging studies [7]. In appropriately selected patients, anastomotic leaks can be managed with nonoperative treatment, whereas extensive leaks from the gastric conduit require revisional surgery that carries a high mortality rate [8].

\section{Conclusions}

Esophageal stents can play an integral role in the management of anastomotic leaks after esophageal resection for cancer. Success depends on adequate drainage of the abscess, appropriate procedures for source control, and in our case, stent placement.

\section{Additional Information \\ Disclosures}

Human subjects: Consent was obtained by all participants in this study. Conflicts of interest: In compliance with the ICMJE uniform disclosure form, all authors declare the following: Payment/services info: All authors have declared that no financial support was received from any organization for the submitted work. Financial relationships: All authors have declared that they have no financial relationships at present or within the previous three years with any organizations that might have an interest in the submitted work. Other relationships: All authors have declared that there are no other relationships or activities that could appear to have influenced the submitted work.

\section{References}

1. Milek T, Ciostek P, Petryka R: Results of endoscopic and surgical fistula treatment in oesophagointestinal anastomosis after gastrectomy. Wid In Tech Malo. 2015, 10:515-520.

2. Turkyilmaz A, Eroglu A, Aydin Y: The management of esophagogastric anastomotic leak after esophagectomy for esophageal carcinoma. Dis Esophagus. 2009, 22:119-26. 10.1111/j.14422050.2008.00866.x

3. Alanezi K, Urschel JD: Mortality secondary to esophageal anastomotic leak. Ann Thorac Cardiovasc Surg. 2004, 2:71-5.

4. Kauer WK, Stein HJ, Dittler HJ: Stent implantation as a treatment option in patients with thoracic anastomotic leaks after esophagectomy. Surg Endosc. 2008, 1:50-3. 10.1007/s00464-007-9504-5

5. Lerut T, Coosemans W, Decker G: Anastomotic complications after esophagectomy. Dig Surg. 2002, 2:92-8. $10.1159 / 000052018$

6. Patil P, Patel S, Mistry R: Cancer of the esophagus: esophagogastric anastomotic leak--a retrospective study of predisposing factors. J Surg Oncol. 1992, 3:163-7.

7. Martin L, Swisher S, Hofstetter W: Intrathoracic leaks following esophagectomy are no longer associated with increased mortality. Ann Surg. 2005, 3:392-402. 10.1097/01.sla.0000179645.17384.12

8. Griffin S, Lamb P, Dresner S: Diagnosis and management of a mediastinal leak following radical oesophagectomy. Br J Surg. 2001, 88:1346-51. 